\title{
Antibiotic Residues in Locally Marketed Fresh and Frozen Livers in Cairo and Giza, Egypt
}

\author{
MH Ahmed ${ }^{1 *}$, EM Riad $^{1}, \mathrm{OM} \mathrm{Diab}^{2}$, HA Mansour $^{3}$ and MKh El-Mossalami ${ }^{3}$ \\ ${ }^{1}$ Department of Bacteriology, Animal Health Research Institute, Dokki, Giza, Egypt \\ ${ }^{2}$ Department of Food Hygiene, Animal Health Research Institute, Dokki, Giza, Egypt \\ ${ }^{3}$ Department of Food Hygiene and Control, Faculty of Vet. Medicine, Cairo University, Giza, Egypt \\ *Corresponding author: mohamedhussein_1212@yahoo.com
}

Article History: 21-301 Received: 12-Apr-21 Revised: 11-Jun-21 Accepted: 23-Jun-21
ABSTRA C T
This study was performed to detect the antibiotic residues in marketed fresh and frozen liver samples using
microbiological bioassay method. One hundred fresh and frozen beef liver samples $(50$ samples for each) were examined
by microbiological bioassay for antibiotic residues, 20 fresh samples $(40 \%)$ react positive and 2 frozen samples $(4 \%)$
were positives. Tetracyclines residues were found in all positive fresh and frozen liver samples with an average of
$28.7 \pm 5.5$ and $14.9 \pm 5.7 \mu \mathrm{g} / \mathrm{g}$ for fresh and frozen liver samples respectively. Aminoglycosides (Gentamycin) residues
were found in 1 fresh liver sample $(2 \%)$ with a concentration $35 \mu \mathrm{g} / \mathrm{g}$ while not found in frozen liver samples. The HPLC
technique was used for all positive samples for detection of oxytetracycline residue. All positive samples were above
the permissible limit according to (National Organization of Food Safety Resolution (13/2020). Effect of cooking has a
great effect on elimination of oxytetracycline while freezing has lower effect on oxytetracycline.

Key words: Antibiotic, Oxytetracycline, Liver, Residue, Bioassay.

\section{INTRODUCTION}

The requests for edible offals are increasing with fast growing population. Edible offals could be sold commercially for animal and human nutrition and are economically more profitable. Animal byproducts are rich sources of trace elements; the levels of the trace elements are mostly much greater in animal offal than in muscular tissues (Wioletta et al. 2019). Cattle liver in our society is the most common widely used edible offals. Animal liver is a rich source of protein, which provides the body with energy to maintain cellular functions and it is also rich in vitamins and minerals (Hassan et al. 2020). Health-risk related drugs administration like antibiotics are repeated problems in animal production as those drugs are used to minimize breeding costs and to maximize the productivity (Toffolatti et al. 2006).

Antibiotics are used in veterinary medicine for prophylaxis and treatment of various diseases, and they might be used as feed additives and growth promoters. Antibiotics used for animal production are listed by generic groups as follows: 1) Beta-lactams including penicillins and cephalosporins are bactericidal acting on cell wall synthesis. 2) Tetracyclines including tetracycline, oxytetracycline, doxycycline, chlortetracycline, rolitercycline and minocycline are bacteriostatic broadspectrum antibiotics. 3) Aminoglycosides including streptomycin, dihydrostreptomycin, gentamicin, neomycin, kanamycin, tobramycin, spectinomycin, amikacin, netilmycin, apramycin and paromycin are effective against Gram negative bacteria and are rarely absorbed from intestine. 4) Macrolides including erythromycin, tylosin, oleandomycin, josamycin, troleandomycin, kitasamycin, spiramycin and rosaramicin are bacteriostatic and mainly effective against Gram positive bacteria and to some extent against Gram negative bacteria (Lee et al. 2001).

Tetracyclines are broad spectrum antibiotics widely used in animal husbandry for growth promotion and for prevention and treatment of diseases. In food-producing animals, it could be orally administrated via drinking water or food, intra mammary infusion or parenterally. Because of enterohepatic circulation, a small amount of administrated dosage may remain in the body tissues for a longer time after administration (Botsoglou and Fletouris 2001). Oxytetracycline is distributed into body tissues and found in high concentration in the excretory organs especially liver (Prescott and Baggot 1993). Several studies detected tetracyclines residues from both bovine tissues and liver samples in varying percentages (Olatoye and

Cite This Article as: Ahmed MH, Riad EM, Diab OM, Mansour HA and El-Mossalami MKH, 2022. Antibiotic residues in locally marketed fresh and frozen livers in Cairo and Giza, Egypt. International Journal of Veterinary Science 11(1): 37-42. https://doi.org/10.47278/journal.ijvs/2021.073 
Ehinmowo 2009; Muriuki et al. 2001; Abbasi et al. 2012; Morshdy et al. 2013; Kimera et al. 2015).

Maximum Residual Limits (MRLs) and withdrawal periods for the use of veterinary medicines shall be considered to avoid unacceptable residues in meat and the consequent consumer' health hazards. According to (FAO/WHO 2000 and National Organization of Food Safety Resolution, 13/2020) the Maximum residue limit (MRL) for tetracycline is set to be as $600 \mu \mathrm{g} / \mathrm{kg}$ for liver tissue.

Bioassay technique, seven plates agar diffusion technique using monolayer plates could detect and quantitate antibiotic residues in meat and poultry byproducts including liver (USDA/FSIS 2011). Bioassay technique is a widely used screening technique for monitoring antibiotic residues in liver tissue because of its simplicity and lower cost. High performance liquid chromatography (HPLC) is preferred not only for its capability to analyze thermolabile compounds, but also for its specific, certain and sensitive power (Sirmagül 2010; Sara and Antonio 2009).

Heat treatments like microwaving, boiling and roasting were the effective heat treatment methods on degrading oxytetracycline residues to safe level. Therefore, efficient heat treatment of meat is highly recommended before serving to human to minimize the risk of antibiotic residues in animal tissue (Martin et al. 1996; Abou-Raya et al. 2013; Nashwa et al. 2016; Tian et al. 2017; Vivienne et al. 2018; Heba et al. 2019). Boiling and frying cause reduction in antibiotic residues concentrations owing to migration of the antibiotic residues from tissue to cooking medium (water and oil). The effect of freezing on oxytetracycline resulting in lower reduction effect (Shaltout et al. 2019; Heba et al. 2019). OTC residue not detected after freezing of liver from rabbit for 1 month after 3 Weeks of its injection by OTC (Morshdy et al. 2014).

The main public health significances of antibiotic residues are development of hypersensitivity reaction and antibiotic resistance, mutagenicity, carcinogenicity, teratogenicity and disruption of intestinal normal flora (Beyene et al. 2016). The objective of the present study was to investigate the qualitative and quantitative detection of antibiotic residues in marketed fresh and frozen beef liver using the microbiological bioassay and HPLC. Also, to clarify the effect of heat treatment and frozen storage on liver tissues containing antibiotic residues.

\section{MATERIALS AND METHODS}

\section{Collection of Samples}

Fresh and frozen cattle liver samples (fifty each) were randomly collected from meat shops and supermarkets at Cairo and Giza Governorates, Egypt. Every sample was packed separately in a sterile plastic bag then, labeled and transferred as soon as possible in an ice-box to the laboratory.

\section{Detection of Antibiotic Residues in Cattle Liver Samples} by Bioassay Method: According to (USDA/FSIS 2011).

The test principle based on the presence or absence of an inhibition zone on seeded plates with sensitive bacteria. The presence of an inhibition zone can indicate the presence of different antimicrobial group residues according to the seeded plates.

\section{Seven Plate Bioassay Systems}

Plate 1 with B.cereus and Penicillinase at $\mathrm{pH} 4.5$ for Tetracycline residue detection, Plate 2 with $K$. rhizophila at $\mathrm{pH} 6$ for Beta-Lactam residues detection, Plate 3 with $K$. rhizophila and Penicillinase at $\mathrm{pH} 6$ for Beta-Lactam residues detection, Plate 4 with $B$. subtilis and Penicillinase at $\mathrm{pH} 8$ for Streptomycin or Dihydrostreptomycin residues detection, Plate 5 with $K$. rhizophila ATCC 9341a \& Penicillinase at $\mathrm{pH} 8$ for Erythromycin residues detection, Plate 6 with $K$. rhizophila ATCC 15957 \& Penicillinase at $\mathrm{pH} 8$ for Tylosin residues detection, and Plate 7 with $S$. epidermidis and Penicillinase at $\mathrm{pH} \quad 8$ for Aminoglycoside's residues detection.

\section{Microorganisms Used for the Bioassay System}

a) K. rhizophila (formerly Micrococcus luteus), ATCC 9341a (KR)

b) K. rhizophila, ATCC 15957 (KRER)

c) S. epidermidis, ATCC 12228 (SE)

d) B. cereus, ATCC 11778 (BC)

e) B. subtilis, ATCC 6633 (BS)

\section{Reading the Bioassay}

1) After incubation of the plates, the spiders or cylinders were removed by inverting the plates in a bucket. The spiders or cylinders were covered in the bucket with distilled water, then, decontaminated by autoclaving or chemically, 2). The test plates were arranged according to consecutive numbers of the plates, 3) The plates were read starting clockwise from the first well at the marked line and read the zone of inhibition, 4) Use the caliper to record the diameter of each zone of inhibition (to the nearest millimeter) for both the unknown and the standard reference antibiotic, and 5) The prepared standard curve is used to calculate the quantitative determination the results.

Detection of Oxytetracycline Residue in Cattle Liver Samples by HPLC Method: According to (FSIS 2011)

1. Preparation of Controls: Five $\pm 0.1 \mathrm{~g}$ of blank liver tissue was weighed (analyzed previously and has no oxytetracycline residues) into two polypropylene tubes $(50 \mathrm{~mL})$. One tube is used as -ve control and the other tube is fortified with $100 \mu \mathrm{L}$ of $0.5 \mathrm{ppm}$ standard for detection the percent of recovery.

2. Identification and Calculation: 1) The percent of recovery of oxytetracycline which is fortified with $0.5 \mathrm{ppm}$ was calculated using the peak height or area of chromatograms of the same concentrations of standards, and 2) to identify the sample as positive, the following criteria were used a) of each analyte at $0.5 \mathrm{ppm}$ level, the recovery percent should be $\geq 20 \%$, b) at $0.5 \mathrm{ppm}$ level, the signal to noise ratio(s) should be $>3$, and c) the retention time of oxytetracycline recovery should be matched with the retention time of sample peak(s) within $\pm 0.2 \mathrm{~min}$.

\section{Heat treatment \& freezing storage of positive samples}

The positive raw samples were selected for cooking and freezing methods then performed HPLC analysis for processed samples like raw samples after completing thermal processing of them. 1) Cooking (Grilling): 15-20g of positive liver samples were placed onto a grill and cooked for $15 \mathrm{~min}$, then removed and allowed to cool and 
examined for the detection of antibiotic residues by HPLC method, and 2) Freezing: $100 \mathrm{~g}$ of positive liver samples were kept in the freezer at $\left(-20^{\circ} \mathrm{C}\right)$ and examined by HPLC method monthly till disappearing of oxy-tetracycline residues or obtaining the same oxytetracycline residue concentrations in two consecutive months.

\section{RESULTS AND DISCUSSION}

Antibiotics were added to feeds that cause growthstimulating effects by preventing infectious diseases at lower doses than therapeutic ones. Induction of antimicrobial resistant bacteria and inactivation of human intestinal flora are major concerns affecting human health. Regulatory guidelines, such as ADIs and MRLs, were reflecting the effect on human intestinal bacteria (Jeong et al. 2010). The bacteria, which resist the antimicrobial drugs was represented a reservoir of transmissible resistance genes for pathogenic or commensal bacteria in the gastrointestinal tract (Alvarez et al. 2013) and thus represented an intermediate solution in the treatment of bacterial infection.

In this study a total of 100 random samples of fresh and frozen liver (50 samples of each) obtained from abattoirs and supermarkets in Cairo and Giza governorates were examined for detection of antibiotic residues (Table 1). Results of antibiotic residues using microbiological bioassay in fresh and frozen beef liver samples presented in Table 1 revealed that oxytetracyclines could be detected in 20 fresh and 2 frozen liver samples, however only one fresh liver sample was positive for aminoglycosides residues. B-Lactams and macrolides failed to be detected from all the examined liver samples. Nearly similar result was recorded by Elnasri et al. (2014) from liver tissue samples $(28.3 \%)$.

Higher results were reported by Abbasi et al. (2012) $(31.8 \%)$ for tetracyclines residue from liver samples. Also, Muriuki et al. (2001) could detect tetracyclines residue from $(45.6 \%)$ beef samples of which $24 \%$ were liver samples. However, lower results were obtained from slaughtered cattle tissue samples $(8.3 \%)$ by Oboegbulem and Fidelis (1996), from beef liver samples $(7.66 \%)$ by (Mohamed et al. 2011), from cattle muscle and kidney tissue samples $(0.6 \%)$ by Piotrowska et al. (2011), from cattle liver tissue samples ( $8 \%$ ) by Polakova et al. (2014), oxytetracycline residues were detected in $(2 \%)$ from examined bovine tissues by Morshdy et al. (2013) and from fresh bovine liver samples $(5 \%)$ while not detected in frozen bovine liver samples (El Atabani et al. 2014).

From the results recorded in Table 2 and Table 3, it's evident that the mean concentrations of oxytetracyclines residue are $28.7 \pm 5.5$ and $14.9 \pm 5.7 \mu \mathrm{g} / \mathrm{g}$ for fresh and frozen liver samples respectively while the concentration of aminoglycosides (Gentamycin) residue was $35 \mu \mathrm{g} / \mathrm{g}$ for fresh liver sample, however it could not be identified from frozen liver samples.
Table 1: Antibiotic residues in all samples of fresh and frozen liver using microbiological bioassay $(n=100)$

\begin{tabular}{lcccc}
\hline Antibiotic Group & \multicolumn{4}{c}{ No. of Positive samples } \\
\cline { 2 - 5 } & Fresh samples & $\%$ & Frozen samples & $\%$ \\
\hline Tetracyclines & 20 & 40 & 2 & 4 \\
B-Lactams & 0 & & & 0 \\
Aminoglycosides & 1 & 2 & & 0 \\
Macrolides & 0 & & & 0 \\
\hline
\end{tabular}

Table 2: Tetracyclines residue levels $(\mu \mathrm{g} / \mathrm{g})$ in the positive samples of fresh and frozen liver samples using microbiological bioassay

\begin{tabular}{lcccccc}
\hline Samples & $\begin{array}{c}\text { Total } \\
\text { number }\end{array}$ & $\begin{array}{c}\text { No. of +ve } \\
\text { samples }\end{array}$ & $\%$ & Min. Max. Mean \pm SE \\
\hline Fresh liver & 50 & 20 & 40 & 14.8 & 54.8 & $28.7 \pm 5.5$ \\
Frozen liver & 50 & 2 & 4 & 9.2 & 20.6 & $14.9 \pm 5.7$ \\
\hline
\end{tabular}

Table 3: Aminoglycoside's residue levels $(\mu \mathrm{g} / \mathrm{g})$ in the positive samples of fresh and frozen liver samples using Microbiological Bioassay

\begin{tabular}{lcccc}
\hline Samples & $\begin{array}{c}\text { Total } \\
\text { number }\end{array}$ & Positive samples & \% Concentration \\
\hline Fresh liver & 50 & 1 & 2 & 35 \\
Frozen liver & 50 & 0 & 0 & 0 \\
\hline
\end{tabular}

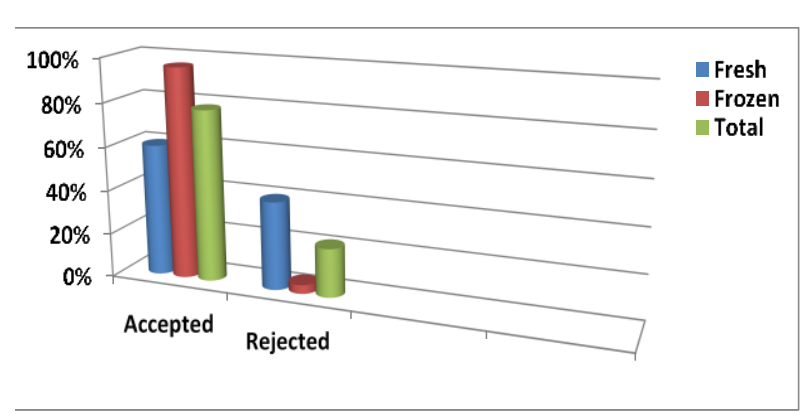

Fig. 1: Accepted and rejected liver samples (\%) due to antibiotic residues.

Tetracycline is associated with changes in peripheral blood, changes in the color of bones and teeth due to binding to calcium ions, and allergic reactions in humans. Low doses (20 mg oxytetracycline/person/day) were affect human fecal anaerobic microflora in gastrointestinal tract of human. These observations are used to determine the acceptable daily intake for humans of $0.003 \mathrm{ppm}$ (David and Scott 1994; Wlatner-Tows and Mc Ewen 1994; Muriuki et al. 2001; Samanidou et al. 2007).

Table 4 showed that using HPLC, oxytetracycline residue could be identified from $90 \%$ of tetracyclines positive fresh liver samples with a concentration of $33.9 \pm 3.4 \mu \mathrm{g} / \mathrm{g}$ while it could not be recognized in positive frozen samples.

It is worthy to mention that the maximum residue limit for tetracyclines residue in cattle liver is $600 \mu \mathrm{g} / \mathrm{kg}$ and that for aminoglycosides residue is $200-2000 \mu \mathrm{g} / \mathrm{kg}$ (FAO/WHO 2000). Consequently, all positive examined liver samples were exceeding the permissible limit and should be rejected (Table 5). Higher concentrations were obtained by (Olatoye and Ehinmowo 2009; Olatoye and Ogundipe 2013; El Atabani et al. 2014; Kimera et al. 2015).

Table 4: Oxytetracycline levels $(\mu \mathrm{g} / \mathrm{g})$ in the positive tetracyclines samples of fresh and frozen liver using HPLC

\begin{tabular}{|c|c|c|c|c|c|c|}
\hline Samples & No. of TC positive samples & No. of OTC positive samples & $\%$ & Min. & Max. & Mean \pm SE \\
\hline Fresh liver & 20 & 18 & 90 & 23.4 & 48.7 & $33.9 \pm 3.4$ \\
\hline Frozen liver & 2 & 0 & 0 & 0 & 0 & 0 \\
\hline
\end{tabular}

TC: Tetracyclines; OTC: Oxytetracycline. 
Table 5: Accepted and rejected samples due to antibiotic residues in liver samples

\begin{tabular}{|c|c|c|c|c|c|}
\hline \multirow[t]{2}{*}{$\begin{array}{l}\text { Sample } \\
\text { Type }\end{array}$} & \multirow[t]{2}{*}{ No. } & \multicolumn{2}{|c|}{$\begin{array}{l}\text { Samples } \\
\text { Accepted }\end{array}$} & \multicolumn{2}{|c|}{$\begin{array}{l}\text { Samples } \\
\text { Rejected }\end{array}$} \\
\hline & & No. & $\%$ & No. & $\%$ \\
\hline Fresh liver & 50 & 30 & 60 & 20 & 40 \\
\hline Frozen liver & 50 & 48 & 96 & 2 & 4 \\
\hline Total & 100 & 78 & 78 & 22 & 22 \\
\hline
\end{tabular}

The level of antibiotic residues is highest in liver samples because of the role of the liver in the metabolism and detoxification of most antibiotics by its microsomal enzymes which lead to higher levels of antibiotic residues through its tissues (Salama et al. 2011). This high incidence result of tetracycline residues may be due to its uses in the treatment of Rickettsia, Spirochetes, Mycoplasma and Chlamydia infections and its uses as broad-spectrum antimicrobial in all veterinary clinics and produced on large scale by many pharmaceutical companies (Hsu 2008). The effect of cooking by grilling on antibiotic residues in liver samples is highly effective to eliminate up to $100 \%$ of oxytetracycline residues which agree with (Javadi et al. 2009) who couldn't detect OTC in positive liver tissue after roasting.

Table 6: Effect of freezing $\left(-20^{\circ} \mathrm{C}\right)$ on oxytetracycline residues in positive samples $(\mu \mathrm{g} / \mathrm{g})$ using HPLC

\begin{tabular}{lcc}
\hline Month & Residues & Reduction (\%) \\
\hline First & $32.7 \pm 3.3$ & 3.4 \\
Second & $32.5 \pm 3.3$ & 4.0 \\
Third & $31.0 \pm 3.1$ & 8.7 \\
\hline $0-$ time Residues reading & $33.9 \pm 3.4$ &
\end{tabular}

0-time Residues reading: $33.9 \pm 3.4$.

Nearly similar results reported by Vivienne et al. (2018) for OTC residue in liver tissues. Also, Heba et al. (2019) and Shaltout et al. (2019) recorded a great reduction for OTC residue in meat caused by different cooking methods. Moreover, OTC residue not detected after boiling of liver from rabbit after 3 Weeks of its injection by OTC (Morshdy et al. 2014). Lower result reported by Khan et al. (2015) who reported that OTC residue level in broiler liver reduction percent by grilling is $33 \%$, by roasting is $55 \%$, by boiling is $62 \%$ and by microwaving is $64 \%$.

Boiling and roasting of meat samples has a greater effect on reduction of oxytetracycline residues (Vivienne et al. 2018). Besides, Microwaving was more effective on oxytetracycline residues than boiling and roasting (AbouRaya et al. 2013).

Furthermore, conventional sterilization at lowtemperature, long-time treatment would destroy more than $98 \%$ of the initial concentration of oxytetracycline residues while Ultra Heat Treatment (UHT) at high-temperature, short-time treatment would leave unaffected residues in the 50-90\% range (Hassani et al. 2008). Although cooking will degrade antibiotic residues, it is converted to its metabolites which may be more harmful on human health than antibiotic itself. Degradation of oxytetracycline residues by cooking resulted in formation of degradation products (alfa and beta-apo-OTC) with a concentration of 0.7 to $1.2 \%$ of initial OTC content. Beta-apo-OTC could damage kidney and liver tissues of rats and lead to necrosis and degeneration of hepatocytes (Van Boeckel et al. 2015). Oxytetracycline residues in vegetable oil and water are not stable. In vegetable oil more stable at $180^{\circ} \mathrm{C}$ with a half- life of $8 \mathrm{~min}$ and in water at $100^{\circ} \mathrm{C}$ with a half-life of $2 \mathrm{~min}$ (Martin et al. 1996).

Degradation rate of antibiotic residues for aqueous matrix at $100^{\circ} \mathrm{C}$ were $\beta$-lactams equal to tetracycline (most heat-labile) more than lincomycin more than amphenicols more than sulfonamides (most heat-stable). Degradation of by-products is still present although thermal processing resulted in minimizing the concentration of parent residues of antibiotics. Some of these by-products causing hazards for human health. So, further investigations will be needed to determine their risk on human health (Tian et al. 2017).

Effect of freezing (Table 6) at $-20^{\circ} \mathrm{C}$ has low effect on oxytetracycline residues as it decreased by only $3.4 \%$ after first month of freezing then reduced by $4 \%$ and $8.7 \%$ after second and third month respectively. Nearly similar result was stated by (Shaltout et al. 2019) where OTC residue concentration in meat reduced by $2.05 \%$ after freezing for 6 months. Higher result was described by (Morshdy et al. 2014) where OTC residue not detected after freezing of liver from rabbit for 1 month after 3 Weeks of its injection by OTC.

\section{Conclusion and Recommendations}

In conclusion the present study indicated that some local and imported bovine liver samples contain antibiotic residues and such residues were at levels exceeding the permissible limits. Moreover, it is of great importance to denote that most of antibiotic distinguished was from tetracyclines group and mainly oxytetracycline. However, cooking was sufficient to eliminate oxytetracycline residue completely, but it might be incapable to eliminate or reduce its metabolites that may be more hazardous to human health. It is commendable to mention that fresh liver had more antibiotic residues than frozen one. Such observation specified the unawareness of withdrawal period which could lead to a serious threat for consumers. Therefore, antibiotic residues monitoring in bovine liver is a challenging and necessary issue to safeguard consumers' health as well as minimize negative impact of antibiotics usage for food animal.

\section{Acknowledgments}

The authors would like to thank Dr. Gehad Fathy (Chief Researcher and Quality Manager in Food Hygiene Department, AHRI) for her assistance in the Bioassay method.

\section{Author's Contribution}

All authors actively participated in the execution of the project, manuscript writing and revision. All authors approved final version of the manuscript.

\section{REFERENCES}

Abbasi MM, Nemati M, Babaei H, Ansarin M and Nourdadgar A, 2012. Solid-Phase Extraction and Simultaneous Determination of Tetracycline Residues in Edible Cattle Tissues Using an HPLC-FL Method. Iranian Journal of Pharmaceutical Research 11: 781-787.

Abou-raya SH, Shalaby AR, Salama NA, Emam WH and Mehaya FM, 2013. Effect of ordinary cooking procedures on tetracycline residues in chicken meat. Journal of Food and Drug Analysis 21: 80-86. 
Alvarez FE, Cancelo A, Díaz VC, Capita R and Alonso CC, 2013. Antimicrobial resistance in E. coli isolates from conventionally and organically reared poultry: A comparison of agar disc diffusion and Sensi Test Gram-negative methods. Food Control 30: 227-234. https://doi.org/ 10.1016/j.foodcont.2012.06.005

Beyene T, Sultan A, Dinka A, Tariku J and Fanos T, 2016. Assessment of Rational Veterinary Drugs Use in Livestock at Adama District Veterinary Clinic, Central Ethiopia. Journal of Veterinary Science and Technology 7: 2157-7579.

Botsoglou NA and Fletouris DJ, 2001. Drug Residues in Foods: Pharmacology, Food Safety and Analysis. Food science and technology (Marcel Dekker) 102: 94-101, 526-529, 9851001.

David A and Scott E, 1994. Distribution and fate of growth promoting drugs in nutrition at drug interrelations. Israel Journal of Veterinary Medicine 44: 139-140.

El Atabani AI, El-Ghareeb, WR, Elabbasy MT and Ghazaly EI, 2014. Oxytetracycline residues in marketed Frozen beef livers at Sharkia, Egypt. Benha Veterinary Medical Journal 26: 104-112.

Elnasri H, Salman A and El Rade S, 2014. Screening of Antibiotic Residues in Poultry Liver, Kidney and Muscle in Khartoum State, Sudan. Journal of Applied and Industrial Sciences 2: 116-122.

FAO/WHO, 2000. Joint FAO/WHO Food Standards Programme Codex Committee on residues of veterinary drugs in foods, $12^{\text {th }}$ Session, Washington, D.C., consideration of maximum residue limits for veterinary drugs at steps 7 and 4, maximum residue limits for veterinary drugs at various steps.

Food Safety and Inspection Service, 2011. Qualitative identification of tetracyclines. GLC-TET2.04. Revision: 4, Replaces: CLG-TET2.03.

Hassan MA, Reham AA and Amera MM, 2020. Assessment of chemical quality of local frozen cattle's liver. Benha Veterinary Medical Journal 38: 97-100.

Hassani M, Lázaro R, Pérez C, Condón S and Pagán R, 2008. Thermostability of oxytetracycline, tetracycline and doxycycline at ultrahigh temperatures. Journal of Agricultural and Food Chemistry 56: 2676-2680. https://doi.org/10.1021/jf800008p

Heba MF, Shaltout F and El Shatter M, 2019. Evaluate antibiotic residues in beef and effect of cooking and freezing on it. Benha Veterinary Medical Journal 36: 109-116.

Hsu WH, 2008. Handbook of Veterinary Pharmacology. $1^{\text {st }}$ Ed. Ames, Iowa, USA: Wiley-Blackwell.

Javadi A, Mirzaei $\mathrm{H}$ and Khatibi SA, 2009. Effect of roasting process on antibiotic residues in edible tissues of poultry by FPT method. Journal of Animal and Veterinary Advances 8: $2468-2472$.

Jeong S, Kang D, Lim M, Kang CS and Sung HJ, 2010. Risk assessment of growth hormones and antimicrobial residues in meat. Toxicological Research 26: 301-313. https://doi.org/10.5487/TR.2010.26.4.301

Khan AA, Randhawa MA, Butt MS and Nawaz H, 2015. Impact of various processing techniques on dissipation behavior of antibiotic residues in poultry meat. Journal of Food Processing and Preservation 40: 76-82. https://doi.org/ 10.1111/jfpp. 12585

Kimera ZI, Mdegela RH, Mhaiki CJN, Karimuribo ED, Mabiki F, Nonga $\mathrm{HE}$ and Mwesongo J, 2015. Determination of oxytetracycline residues in cattle meat marketed in the Kilosa district, Tanzania. Onderstepoort Journal of Veterinary Research 82: 911. https://doi.org/10.4102/ojvr. v82i1.911

Lee HJ, Lee MH and Ruy PD, 2001. Public health risk: chemical and antibiotic residue. Asian Australasian Journal of Animal Sciences 14: 402-413. https://doi.org/10.5713/ajas.2001.402

Martin D, Bygrave J, William H and Shearer G, 1996. The effect of cooking on veterinary drug residues in food: 4 .
Oxytetracycline. Journal Food Additives \& Contaminants 13: 275-286. https://doi.org/10.1080/026520 39609374409

Mohamed BWA, Twfig EM and Atif EA, 2011. Detection of antibiotics residues in beef in Ghanawa Slaughterhouse, Khartoum State, Sudan. African Journal of Food Science 5: 574-580. https://doi.org/10.5897/AJFS.9000067

Morshdy AE, El-Atabany AI, Hussein MA and Darwish WS, 2013. Oxytetracycline residues in bovine carcasses slaughtered at Mansoura Abattoir, Egypt. The Japanese Journal of Veterinary Research 61 Suppl: S44-7.

Morshdy AM, Hussein MA and El-Gohary AE, 2014. Studies on oxytetracycline residues depletion in rabbit meat. Assiut Veterinary Medical Journal 60: 158-166.

Muriuki FK, Ogara FK, Njeruh F and Mitema FM, 2001. Tetracycline residue levels in cattle meat from Nairobi slaughter house in Kenya. Journal of Veterinary Science 2: 97-101.

Nashwa MZ, Arwa HN, Saleh SH and Nahla SL, 2016. Experimental study on the effect of different cooking method of oxytetracycline residues in chicken meat. Egyptian Journal of Chemistry and Environmental Health 2: 598-610.

National Organization of Food Safety Resolution No. 13/2020. Egyptian Facts No (257) 15 Nov.2020 for upgraded obligated technical rules for maximum residues limits of antibiotics.

Oboegbulem SI and Fidelis AP, 1996. Detection of antimicrobial residues in poultry meat and slaughter cattle in Nigeria. Meat Science 43: 71-74. https://doi.org/10.1016/0309-1740(95) 00049-6

Olatoye IO and Ehinmowo AA, 2009. Oxytetracycline Residues in Edible Tissues of Cattle Slaughtered in Akure, Nigeria. Internet Journal of Food Safety 11: 62-66.

Olatoye IO and Ogundipe GA, 2013. Quantitative analysis of oxytetracycline residue in beef and chicken meat from cities of southwest Nigeria. Bulletin of Animal Health and Production in Africa 61: 39-48.

Piotrowska J, Mituniewicz T, Sowinska J, Gonkiewicz B, Sobczak $J$ and Wolosiuk R, 2011. Antibiotic residues in animal-derived food in the Warmia and Mazury region in the years 2005-2009. Medycyna Weterynaryjna 67: 318-321.

Polakova Z, Kozarova I and Gondova Z, 2014. Screening of antibiotic residues in animal liver, kidney and muscle by tube microbial inhibition tests. Folia Veterinaria 58: 35-37.

Prescott JF and Baggot JD, 1993. Antimicrobial Therapy in Veterinary Medicine $2^{\text {nd }}$ ed. Iwoa State University Press: Iowa, 215-228.

Salama NA, Abou-Raya SH, Shalaby AR, Emam WH and Mehaya FM, 2011. Incidence of tetracycline residues in chicken meat and liver retailed to consumers. Journal of Food Additives and Contaminants 4: 88-93. https://doi.org/ 10.1080/19393210.2011.585245

Samanidou VF, Nisyriou SA and Papadoyannis IN, 2007. Residue analysis of penicillins in food products of animal origin by HPLC: A Review. Journal of Liquid Chromatography and Related Technologies 30: 1145-1204. https://doi.org/10.1080/10826070701274320

Sara B and Antonio DC, 2009. Recent applications of liquid chromatography-mass spectrometry to residue analysis of antimicrobials in food of animal origin. Analytical and Bioanalytical Chemistry 395: 947-966. https://doi.org/ 10.1007/s00216-009-2930-6

Shaltout FAE, Shatter MAE and Sayed NF, 2019. Impacts of different types of cooking and freezing on antibiotic residues in chicken meat. Journal of Food Science Nutrition 5: 045.

Sirmagül B, 2010. Analysis methods and working principles in therapeutic drug level monitoring. Turkish Pharmacology Association XVII. Pharmacology Education Symposium. Nicosia-Cyprus.

Tian L, Khalil S and Bayen S, 2017. Effect of thermal treatments on the degradation of antibiotic residues in food. Critical 
Int J Vet Sci, 2022, 11(1): 37-42.

Reviews in Food Science and Nutrition 57: 3760-3770. https://doi.org/10.1080/10408398.2016.1164119

Toffolatti L, Rosa Gastaldo L, Patarnello T, Romualdi C, Merlanti R, Montesissa C, Poppi L, Castagnaro M and Bargelloni L, 2006. Expression analysis of androgen responsive genes in the prostate of veal calves treated with anabolic hormones. Domestic Animal Endocrinology 30: 38-55. https://doi.org/ 10.1016/j.domaniend.2005.05.008

United States Department of Agriculture / Food Safety and Inspection Service "USDA/FSIS", 2011. Bioassay for the detection, identification and quantitation of antimicrobial residues in meat and poultry tissue. Microbiology Laboratory Guidebook. Office of Public Health Science.

Van Boeckel TP, Brower C, Gilbert M, Grenfell BT, Levin SA, Robinson TP, Teillant A and Laxminarayan R, 2015. Global trends in antimicrobial use in food animals. Proceedings of National Academy of Sciences 112: 5649-5654. https://doi.org/10.1073/pnas.1503141112

Vivienne EE, Josephine OO and Anaelom NJ, 2018. Effect of temperature (cooking and freezing) on the concentration of oxytetracycline residue in experimentally induced birds. Veterinary World 11: 167-171.

Wioletta B, Ewa CP and Alicja K, 2019. Offal chemical composition from veal, beef, and lamb maintained in organic production systems. Animals 9: 489. https://doi.org/ $\underline{10.3390 / a n i 9080489}$

Wlatner-Tows D and Mc Ewen S, 1994. Residues of antibacterial and antiparasitic drugs in food animal origin a risk assessment. Preventive Veterinary Medicine 20: 219-234. https://doi.org/10.1016/0167-5877(94)90084-1 